\title{
Avaliação de impacto ambiental causado por efluentes da estação de piscicultura Santa Rosa, Santarém/Pará
}

No Brasil, a atividade da piscicultura vem aumentando nos últimos anos, proporcionada pelas condições ambientais, principalmente por conta do clima favorável, e a grande abundância de água, que é essencial para a criação de pescados. A qualidade da água é de grande importância para o sucesso da produção, já que é o meio onde se desenvolve a matéria prima dessa atividade, com isso suas características podem afetar a sobrevivência, reprodução, crescimento, ou seja, as ferramentas de manejo da atividade. Apesar do grande desenvolvimento e estímulo de órgãos especializados, observa-se ainda a carência em relação a informações e atos sobre possíveis impactos ao meio ambiente gerados pela atividade, visto que a água que alimenta os tanques de criação são provenientes de cursos d'água que retornam para o mesmo local, porém nos tanques de criação são acrescentadas várias substâncias, necessárias para o sucesso da produção, e que alteram as características da água, podendo assim causar impactos ambientais. O presente estudo objetivou analisar a qualidade dos efluentes gerados nos tanques de piscicultura e avaliar os possíveis impactos decorrentes desses efluentes sobre o corpo receptor. Todos os procedimentos analíticos foram realizados através de procedimentos padrões, descritos em Standard Methods for the Exammination of the Water and Wastewater (2012), foram coletados água de quatro pontos da Estação de piscicultura Santa Rosa visando obte informações sobre as alterações geradas na entrada de efluentes nos tanques e na saída no corpo receptor. Os resultados que a qualidade dos efluentes gerados nos tanques inciden alterações que possivelmente comprometem o ambiente aquático em relação à quantidade de concentrações de DBO e fósforo total que permaneceram com seus níveis superior do permitido. Na comparação dos pontos de montante (P1) e jusante (P4) os resultados revelaram que ocorre diferenças significativas. Os principais impactos observados foi a eutrofização e comprometimento da qualidade da água do efluente no corpo receptor. Observa-se que mesmo não ocorrendo diferenças significativas nos pontos de montante e jusante, deve-se ter o cuidado no manejo, pois elas estão relacionadas com o meio aquático e na alteração de uma podendo ocasionar na morte dos peixes nos viveiros devido a sua sensibilidade e nas variações precipitadas principalmente do oxigênio dissolvido na água.

Palavras-chave: Qualidade; Piscicultura; Água; IQA; DBO.

\section{Evaluation of impacts caused by effluents of the pisciculture season Santa Rosa, Santarém/Pará}

\begin{abstract}
In Brazil, the activity of fish farming has been increasing in recent years, due to the environmental conditions, mainly due to the favorable climate, and the great abundance of water, which In Brazil, the activity of fish farming has been increasing in recent years, due to the environmental conditions, mainly due to the favorable climate, and the great abundance of water, which is essential for fish farming. Water quality is of great importance for the success of production, since it is the medium where the raw material of this activity is developed, with its characteristics
can affect the survival, reproduction, or growth, ie, the management tools of the activity. Despite the great development and encouragement of specialized agencies, there is still a lack of information and acts on possible impacts to the environment generated by the activity, since the water that feeds the breeding tanks comes from water courses that return to the same place, but in the breeding tanks are added several substances, necessary for the success of the production, and that alter the characteristics of the water, and thus can cause environmental impacts. The present study aimed to analyze the quality of the effluents generated in the fish culture tanks and to evaluate the possible impacts of these effluents on the recipient body. All analytical procedures were performed using standard procedures described in Standard Methods for the Examination of the Water and Wastewater (2012), four-point water was collected from the Santa Rosa Fish Farm Station to obtain information on the changes generated at the effluent inflow the tanks and the outlet in the receiving body. The results that the quality of the effluents remained with their high observed were eutrophication and impaiment of effluent water quality in the recipient body. It should be noted that even though there are no statistically significant differences in upstrean and downstream points, care should be taken in handling them, as they are related to the aquatic environment and in the alteration of one that can cause fish death in the nurseries due to their sensitivity and in the precipitations mainly precipitated from the dissolved oxygen in the water.
\end{abstract}

Keywords: Quality; Pisciculture; Water; AQI; DBO.

Topic: Desenvolvimento, Sustentabilidade e Meio Ambiente

Reviewed anonymously in the process of blind peer.

Edinelson Saldanha Correa (iD

Universidade Federal do Oeste do Pará, Brasil

http://lattes.cnpq.br/0344768485868201

http://orcid.org/0000-0002-4162-4296

edinelson saldanha@hotmail.com

Christiane do Nascimento Monte

Universidade Federal do Oeste do Pará, Brasil

http://lattes.cnpq.br/6178162183692365

http://orcid.org/0000-0003-4840-7777

christiane.monte@yahoo.com.br

Thiago Shinaigger Rocha do Nascimento (D)

Universidade Federal do Oeste do Pará, Brasil

http://lattes.cnpq.br/6476976978923362

http://orcid.org/0000-0002-2691-6039

shinaigger@gmail.com
Received: 02/12/2019

Approved: $12 / 01 / 2020$
Referencing this:

CORREA, E. S.; MONTE, C. N.; NASCIMENTO, T. S. R.. Avaliação de impacto ambiental causado por efluentes da estação de piscicultura Santa Rosa, Santarém/Pará. Revista Ibero Americana de Ciências Ambientais, v.11, n.1, p.260-273, 2020. DOI: http://doi.org/10.6008/CBPC2179-6858.2020.001.0024 


\section{INTRODUÇÃO}

A piscicultura é um ramo da aquicultura que incide entre suas modalidades a atividade da criação de peixes em ambientes artificiais, seja para consumo humano ou para ornamentações em aquários. Essa pratica é registrada desde a Roma Antiga e depois de séculos, em função do crescimento demográfico e da demanda por alimentos (BASTOS, 2003).

A prática em atividades de piscicultura se desenvolveu pelo mundo, por conta da pesca exagerada em lagos, rios e nos oceanos no que provocou a redução dos recursos pesqueiros. Foi a partir daí que, para gerenciar a pesca e seu consumo, passou-se a produzir peixes em ambientes artificiais, esta atividade foi então aos poucos se aperfeiçoando, com metodologias e recursos tecnológicos, até se tornar uma indústria próspera, voltada para a venda de peixes em grandes quantidades (RIRSCH, 2013).

No Brasil a piscicultura vem se desenvolvendo em um ritmo acelerado, pois o índice é muito superior ao alcançado na maioria das demais atividades agropecuárias, já que apresenta boas condições para o desenvolvimento da piscicultura, gerado principalmente pelo clima favorável e o crescente mercado interno, que cria uma interessante vista para investimentos na produção pesqueira (RIRSCH, 2013; SILVA et al., 2018).

Atualmente no estado do Pará, a piscicultura é a atividade aquícola mais importante apresentando uma diversidade de produtores desde o cultivo restrito à subsistência, aos grandes produtores voltados à exportação. Os principais polos de piscicultura estão localizados próximo a Belém, ao longo da bacia do rio Tocantins, próximo ao lago do rio Tucuruí, e na zona metropolitana de Santarém e nos municípios dos seus arredores. Isso se deve principalmente pelo potencial hídrico da região, condições climáticas adequadas e condições geográficas, que favorecem melhor desenvolvimento de vias de acesso, como as estradas, as quais fornecem uma infraestrutura necessária na produção e comercialização, como por exemplo, os fornecedores de ração e alevinos (SILVA, 2010; BRABO, 2014).

A criação de peixes é uma atividade de valor econômico adjunto a piscicultura possui uma boa lucratividade, ainda ser uma medida eficiente de conservação da natureza desde que o planejamento e as técnicas de manejo sejam adequados à realidade de cada região, porém, devemos considerar também que muitas das pessoas que decidem investir na criação de peixes em ambientes artificiais, não possuem informações do que venha a ser criar peixes de boa qualidade, baixo custo e sustentabilidade (SOARES, 2003). Andrade (1989), já apontava que a piscicultura surgiu como uma possibilidade de se transformar numa indústria que movimenta milhões de dólares em diversos países.

De acordo com Queiroz (2004), sobre os principais impactos das atividades de piscicultura são as elevadas concentrações de matéria orgânica e nutrientes (nitrogênio e fósforo) nos efluentes, os quais podem comprometer a qualidade de água dos corpos hídricos à jusante, acelerando o processo de eutrofização, devido, principalmente, à introdução da ração na piscicultura, que cresceu proporcionalmente ao aumento da produção e da produtividade na atividade de aquicultura em todo o mundo. Em sistemas de produção o aporte significativo de nutrientes e matéria orgânica da ração poderá levar ao excesso de fitoplâncton, consequentemente, à baixa concentração de oxigênio dissolvido, à alta concentração de 
amônia, nitrito, nitrato, o que proporciona condições insatisfatórias do sedimento de fundo dos viveiros, pois o sedimento reflete as condições alóctones, como por exemplo processos erosivos das margens, no caso de viveiros em tanque escavados, e também fatores internos, como altas concentrações de sólidos em suspensão na água.

O processo de nitrificação de uma forma geral, afetam a produção e a produtividade, devido à oxidação da amônia, em nitrito e em nitrato, que causa uma diminuição do pH da água. A acidificação da água de cultivo pode causar perdas econômicas consideráveis se o pH for inferior a 6,5 e nos casos de pH abaixo de 4,0 podem causar mortalidade de algumas espécies de peixes (SOUZA, 2010).

Segundo Leira et al. (2017), a qualidade da água é de grande importância para o sucesso da produção, na piscicultura ela é a principal matéria prima da atividade, pois suas características podem afetar de alguma forma a sobrevivência, reprodução, crescimento, produção ou mesmo o manejo dos peixes. Portanto uma avaliação dos recursos hídricos disponíveis para o cultivo vai definir o plano de criação dos peixes. 0 conhecimento e acompanhamento da qualidade dessas águas se fazem imprescindível, não só para evitar surpresas bruscas, como enfraquecimento e morte dos organismos criados, mas também visando a um manejo apropriado do sistema de criação, com melhor utilização da própria água, controle da alimentação e comportamento dos organismos aquáticos.

Apesar do grande desenvolvimento e estímulo de órgãos especializados, observa-se ainda a carência em relação às informações e atos sobre possíveis impactos ao meio ambiente devido a esse tipo de atividade, visto que a água a qual abastece os tanques de criação é proveniente de um curso d'água que retorna para o mesmo com a qualidade deteriorada. Nos tanques são acrescentadas várias substâncias que podem causar danos ao meio ambiente, necessárias para o sucesso dessa atividade, e que alteram as características da água, impactando o corpo receptor (MORAIS, 2015).

Desse modo, o monitoramento da qualidade da água nos empreendimentos aquícolas deve ser frequente, e atender à legislação vigente, especialmente as Resoluções CONAMA (Conselho Nacional do Meio Ambiente) 357/2005 e a 430/2011, para que a atividade não seja apontada e penalizada como causadora de impactos ambientais nos corpos hídricos (BRASIL, 2005; BRASIL, 2011).

A qualidade da água reflete os efeitos agregados de vários processos ao longo do caminho percorrido pela mesma e é influenciada pelas características da bacia hidrográfica (MASSOUD, 2012). Desta forma, torna-se relevante avaliar a qualidade de água para ajusta-las aos seus respectivos usos (SINGH et al., 2005). Desta forma, segundo Lopes (2008), no processo de avaliação da qualidade das águas superficiais, deve se empregar métodos de compreensão fácil para que a informação possa ser transmitida aos usuários deste recurso, tendo destaque a utilização de índices de qualidade de água (IQA), proposto pela CETESB, os quais tem sido, boa alternativa para acompanhar as alterações na qualidade de água ao longo de uma bacia hidrográfica ou do tempo, sejam elas de origem antrópica ou natural.

Neste sentido, esse estudo teve como objetivo avaliar a qualidade dos efluentes gerados nos tanques de piscicultura, enquadrando-os conforme as resoluções do CONAMA n 357/2005 e 430/2011, mensurando quantitativamente as concentrações de amônia, nitrito, nitrato, nitrogênio total, fosforo total, demanda 
bioquímica de oxigênio, oxigênio dissolvido, turbidez, temperatura, $\mathrm{pH}$, alcalinidade total, condutividade elétrica e sólidos totais dissolvidos e coliformes fecais, para avaliar os possíveis impactos decorrentes desses efluentes sobre o corpo receptor, confrontando os valores destas concentrações nos pontos a montante e jusante dos tanques de piscicultura e através do índice de qualidade de água (IQA) .

\section{MATERIAIS E MÉTODOS}

\section{Localização da área de Estudo}

O desenvolvimento do trabalho foi realizado na estação de piscicultura Santa Rosa, conservada pela Secretaria de Desenvolvimento Agropecuário e da Pesca (SEDAP), localizada na PA-370, Rodovia Santarém Curuá - Una, comunidade de Santa Rosa, situado à 34 km do município de Santarém, no oeste do estado do Pará, entre as coordenadas $\left(2^{\circ} 39^{\prime} 52.5^{\prime \prime} \mathrm{S}\right.$ e $\left.54^{\circ} 33^{\prime} 02.8^{\prime \prime} \mathrm{W}\right)$, podendo ser observado na figura 1.

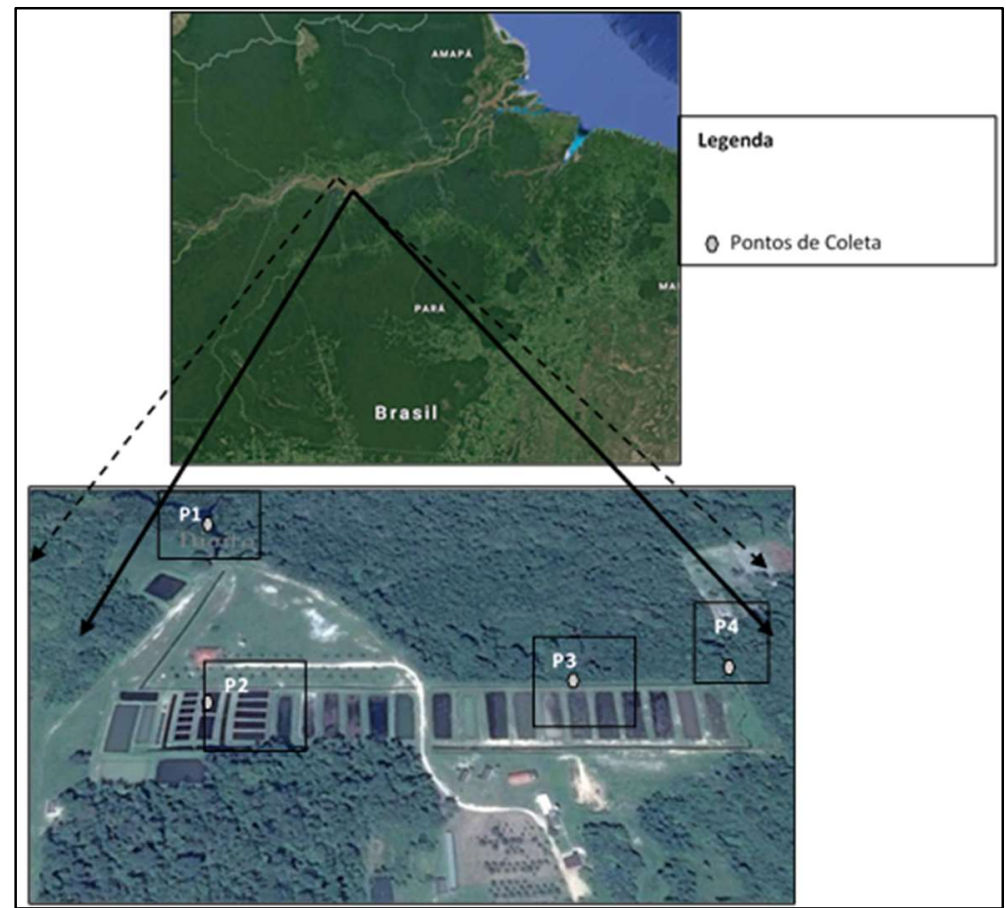

Figura 1: Mapa de Localização Geral dos Pontos de Coleta. Fonte: Google Earth (2018).

Atualmente a estação de piscicultura de Santa Rosa possui 53 tanques que variam entre $6 \mathrm{~m}^{2}$ à 1.280 $\mathrm{m}^{2}$, com profundidade média de 1,5 $\mathrm{m}$, realiza-se cultivo intensivo de peixes, das espécies Tambaqui (Colossoma macropomum), Pirapitinga (Piaractus brachypomus), Curimatá (Prochilodus nigricans), Matrinxã (Brycon cephalus) e Pirarucu (Arapaima gigas), os quais são distribuídos aos piscicultores dos municípios da região oeste do estado do Pará. A figura 2 mostra o fluxograma com o desenvolvimento das etapas deste trabalho iniciando com a coleta das amostras, seguindo o transporte e preservação, bem como, a abordagem dos procedimentos das avaliações dos resultados. 


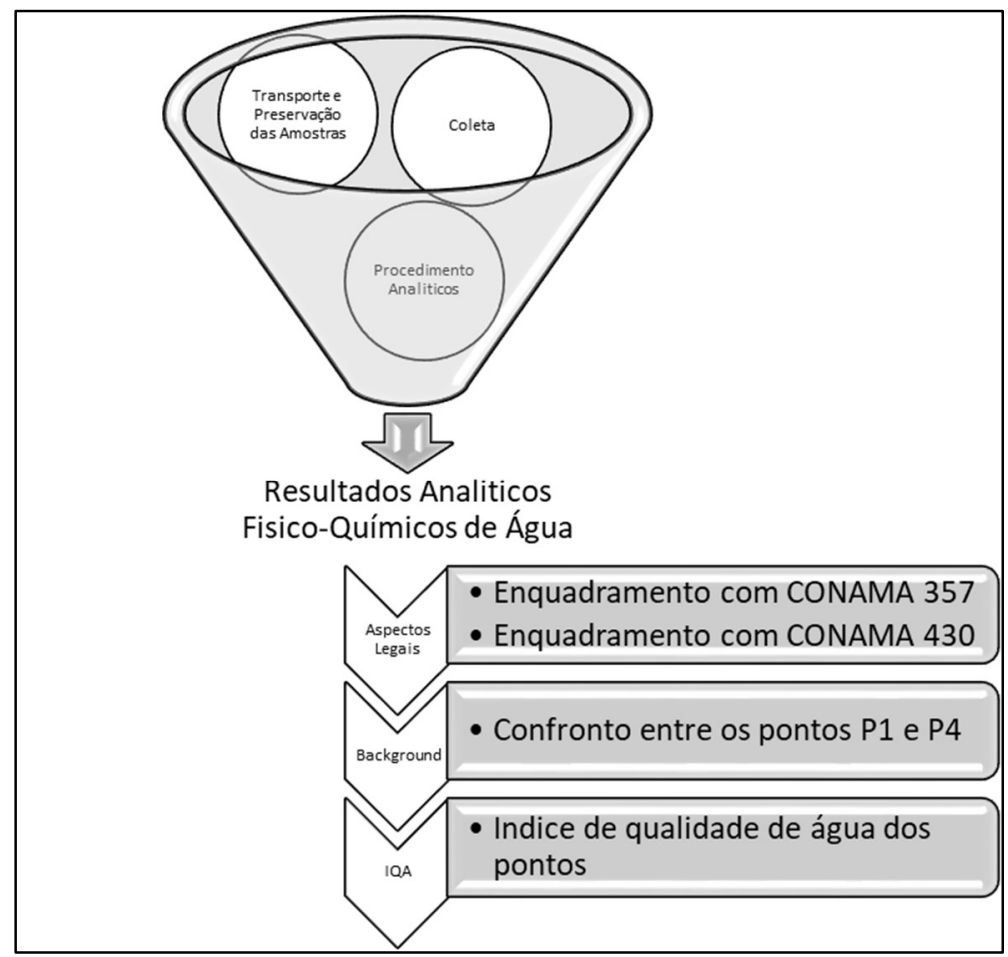

Figura 2: Fluxograma do processo metodológico.

\section{Coleta, transporte e armazenamento}

As amostras foram coletadas entre nos meses de fevereiro e maio (Período chuvoso) e outubro (Período seco) de 2018, sendo tratadas neste com primeira (1), segunda (2), terceira (3) e quarta(4) campanha, para as coletas utilizou-se garrafas de polietileno estéreis de um litro, foram definidos quatro pontos de coletas, sendo o primeiro ponto, o que representa a montante dos tanques (P1), que se refere a água que abastece os tanques de cultivo, ou seja, não sofre influência dos tanques de piscicultura, o segundo e terceiro ponto correspondem a água de dois tanques de cultivo (P2) e (P3) e o quarto que corresponde a jusante do ponto de local de lançamento dos efluentes no corpo receptor (P4), a localização destes pontos podem ser vistos na figura 1. A nomenclatura dos pontos de coleta e campanha serão representadas por PX$\mathrm{Y}$, o qual $\mathrm{X}$ se refere ao local da coleta e $\mathrm{Y}$ o número da campanha, de acordo com o apresentado neste parágrafo.

Todas as coletas foram realizadas pela manhã, sendo que alguns parâmetros foram analisados em campo, já para outros, amostras foram coletadas em frascos de polipropileno, posteriormente conservadas e preservados, conforme recomendações descritas na NBR 9898/87 que trata na preservação e técnicas de amostragem de efluentes líquidos e corpos receptores (ABNT, 1987), transportadas até o laboratório, onde as amostras foram processadas e analisadas.

\section{Procedimentos Analíticos}

Os parâmetros analisados foram os seguintes: Nitrogênio Total, Fosforo Total, Amônia, Nitrito, Nitrato, Temperatura, pH, Turbidez, sólidos totais dissolvidos, Alcalinidade total, Oxigênio Dissolvido, Condutividade e $\mathrm{DBO}_{5}$. A demanda bioquímica de oxigênio $\left(\mathrm{DBO}_{5}\right)$ foi obtida pelo método de incubação por 5 dias a $20{ }^{\circ} \mathrm{C}$, a amônia, nitrato, nitrito e fósforo total foram determinados pelo método de 
espectrofotometria, para determinar a turbidez das amostras se utilizou um turbidímetro digital de bancada, já a alcalinidade total foi realizada através de titulação com ácido sulfúrico. Todos os procedimentos analíticos foram realizados através de procedimentos padrões, descritos em Standard Methods for the Exammination of the Water and Wastewater (APHA, 2012).

As análises físicas, como: aferição de pH, oxigênio dissolvido, temperatura e condutividade elétrica foram realizadas in loco, onde a frequência de oxigênio dissolvido $(\mathrm{mg} / \mathrm{L})$ foi aferida com um oxímetro digital, a temperatura $\left({ }^{\circ} \mathrm{C}\right)$ e $\mathrm{pH}$ foram aferidos com potenciômetro digital e a condutividade elétrica foi obtida com uso de condutivímetro portátil $(\mu \mathrm{S} / \mathrm{cm})$.

\section{Enquadramento Legal}

Os Resultados foram confrontados com os valores de referência das legislações pertinentes estabelecido pelas Resoluções $N^{\circ} 357 / 05$ para aguas de classe 2, para a maioria dos pontos amostrais, excerto o ponto P4 que foi confrontado a resolução 430/11 do Conselho Nacional de Meio Ambiente (CONAMA) e com os valores encontrados no ponto $\mathrm{P} 1$, ou seja, antes de passar pelos tanques de piscicultura e P4 sobre o corpo receptor.

\section{Índice de qualidade de água}

O IQA (índice de qualidade de água), criado pela National Sanitation Foundation (NSF) dos Estados Unidos, é um indicador, que por meio das características físicas, químicas e biológicas fornece ao público um balizador da qualidade das águas de um corpo hídrico (LIBÂNIO, 2005). O IQA pode assumir valores entre 0 e 100, sendo calculo pela seguinte equação:

$$
I Q A=\prod_{i}^{n} q_{i}^{W_{i}}
$$

Onde:

qi: qualidade do i - ésimo parâmetro, um número entre 0 e 100, obtido da respectiva 'curva média de variação de qualidade', em função de sua concentração ou medida, wi: peso correspondente ao $\mathrm{i}$ - ésimo parâmetro, um número entre 0 e 1 , atribuído em função da sua importância para a conformação global de qualidade.

O índice de qualidade de água (IQA) compara a qualidade dos corpos hídricos e monitora as alterações temporais ou espaciais na qualidade da água, refletindo a sua contaminação por ações antrópicas, tais como esgoto doméstico, resíduos industriais ou agropecuários (LOPES et al., 2008; SÁNCHEZ et al., 2007). O IQA desenvolvido pela National Sanitation Foundation (NSF) varia de zero (pior qualidade) a 100 (melhor qualidade) e utiliza nove atributos (oxigênio dissolvido, coliformes termotolerantes, $\mathrm{pH}$, demanda bioquímica de oxigênio, nitrato, fósforo total, temperatura, turbidez e sólidos totais) com seus pesos (Wi) respectivos (CASTRO JUNIOR et al., 2007).

No caso de não se dispor do valor de alguma das nove variáveis, o cálculo do IQA é inviabilizado. A partir do cálculo efetuado, pode-se determinar a qualidade das águas brutas, que é indicada pelo IQA, variando numa escala de 0 a 100, representado na tabela abaixo: A partir do cálculo será determinada a 
qualidade da água, tendo como base a classificação apresentada na Tabela 1.

Tabela 1: Classificação segundo Índice de qualidade de água.

\begin{tabular}{|l|l|}
\hline Classificação do IQA - CETESB \\
\hline Categoria & Ponderação \\
\hline Ótima & $79<1 \mathrm{Q} \leq 100$ \\
\hline Boa & $51<1 \mathrm{QA} \leq 79$ \\
\hline Regular & $36<\mathrm{QQA} \leq 51$ \\
\hline Ruim & $19<\mathrm{QQA} \leq 36$ \\
\hline Péssima & $\mathrm{IQA} \leq 19$ \\
\hline
\end{tabular}

\section{RESULTADOS}

As figuras de 3 a 12 apresentam os parâmetros físico-químicos e microbiológicos, tais como, Nitrogênio Total, Fosforo Total, Amônia, Nitrito, Nitrato, Temperatura, pH, Turbidez, sólidos totais dissolvidos, Alcalinidade total, Oxigênio Dissolvido, Condutividade, $\mathrm{DBO}_{5}$ e coliformes fecais e totais, dos quatros pontos (P1, P2, P3 e P4) amostrais, nas quatro campanhas, bem como, o referido enquadramento junto ao CONAMA 357/05, para rios de classe 2. Já na figura 13 encontra-se os índices de qualidade de água (IQA), para os pontos amostrais.

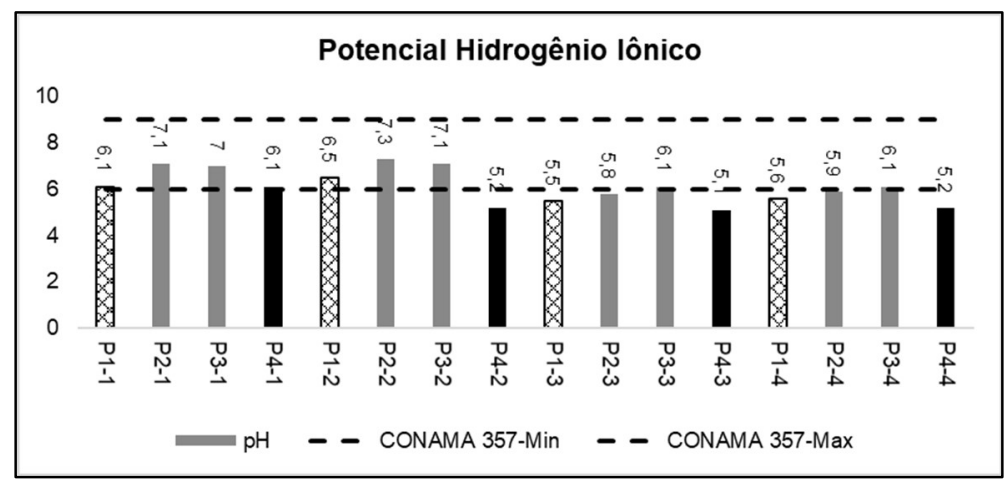

Figura 3: Resultado analítico do potencial hidrogênio iônico dos pontos amostrais nas quatro campanhas.

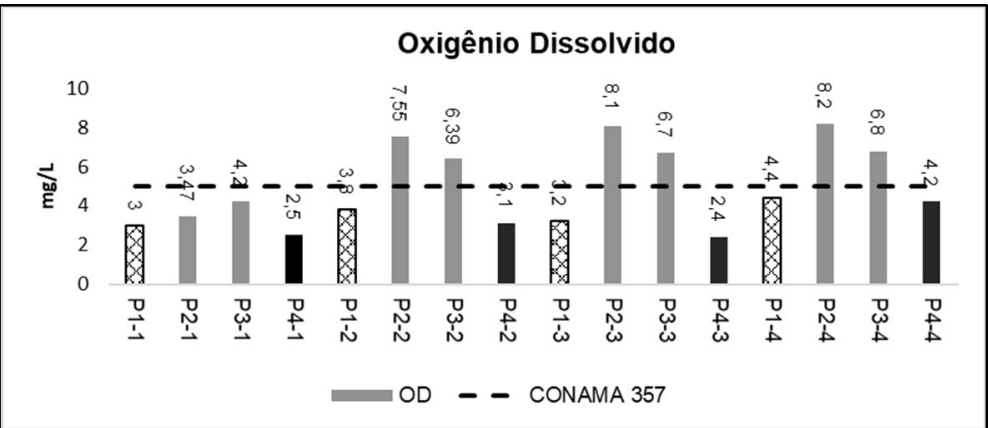

Figura 4: Resultado analítico do oxigênio dissolvido dos pontos amostrais nas quatro campanhas.

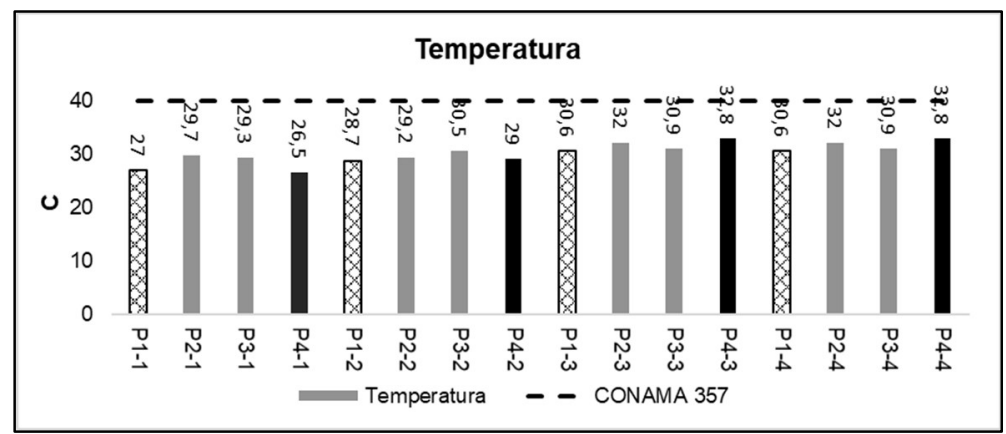

Figura 5: Resultado analítico da temperatura dos pontos amostrais nas quatro campanhas. 


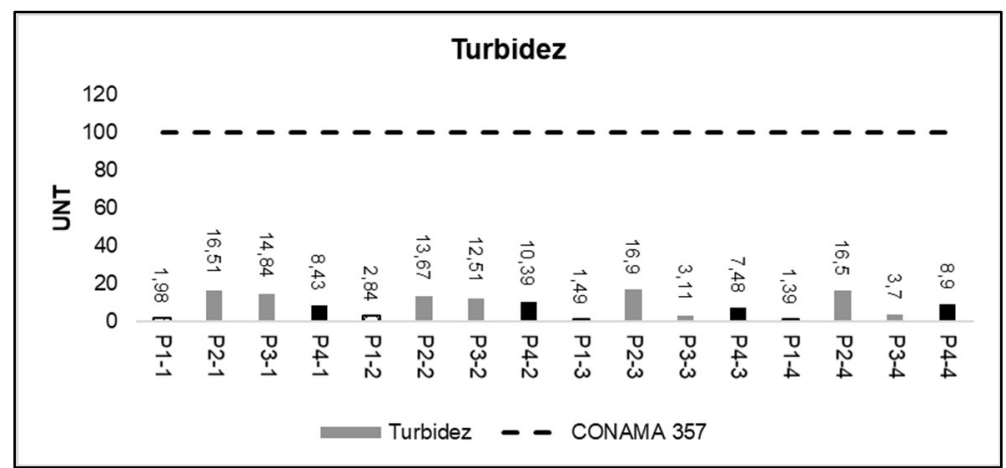

Figura 6: Resultado analítico da turbidez dos pontos amostrais nas quatro campanhas.

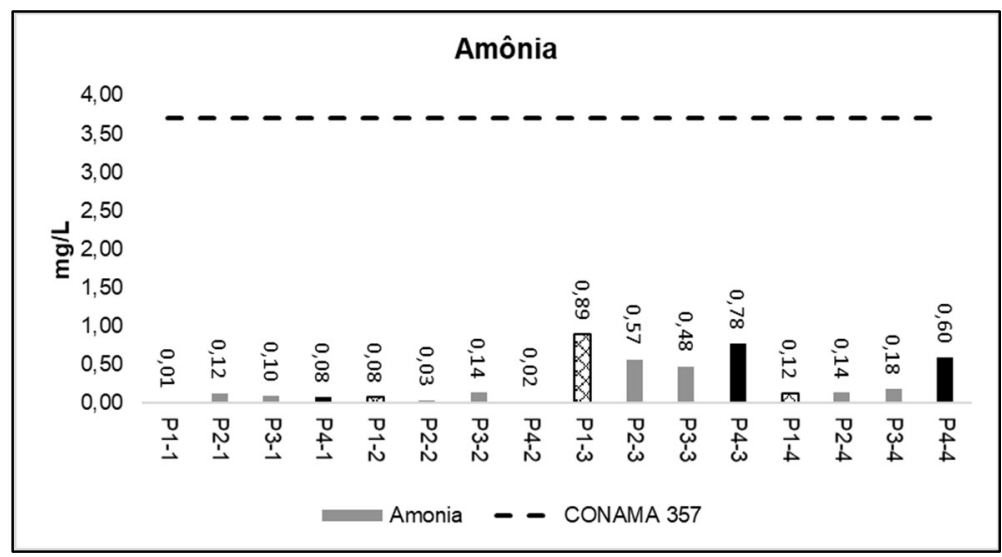

Figura 7: Resultado analítico da amônia dos pontos amostrais nas quatro campanhas.

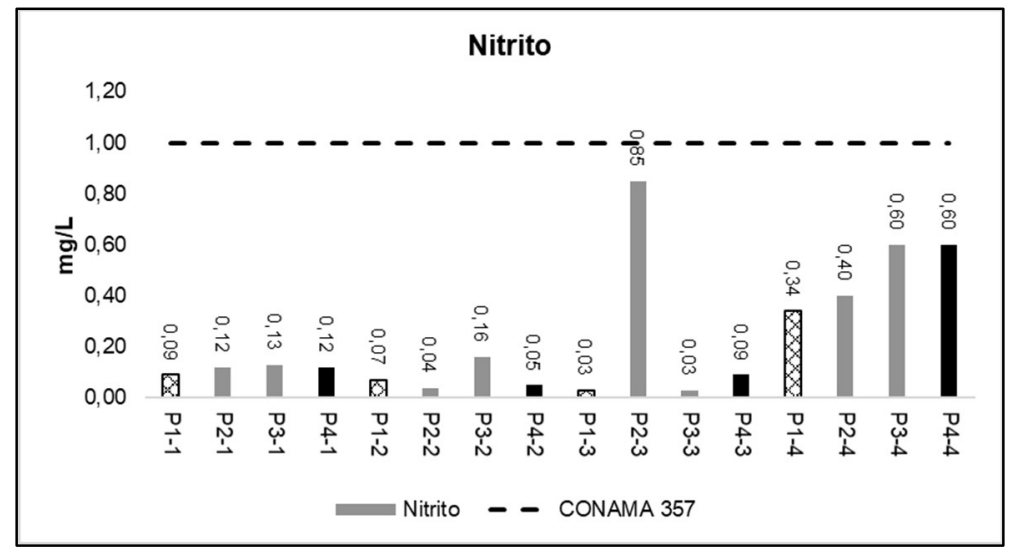

Figura 8: Resultado analítico das concentrações nitrito dos pontos amostrais nas quatro campanhas.

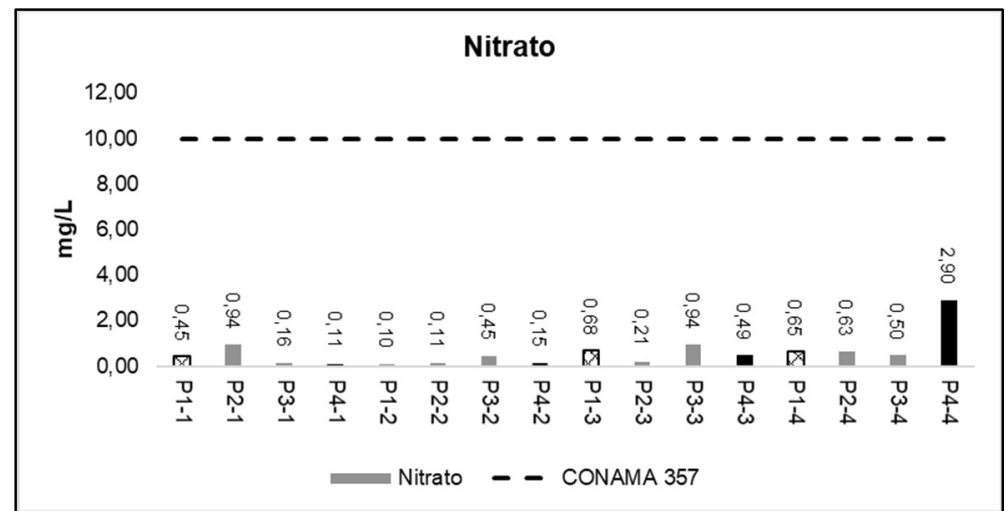

Figura 9: Resultado analítico das concentrações nitrato dos pontos amostrais nas quatro campanhas. 


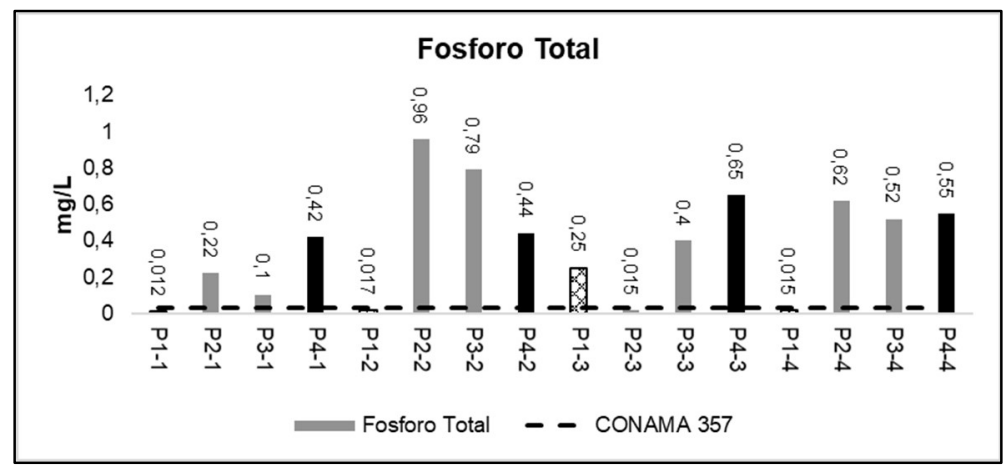

Figura 10: Resultado analítico das concentrações fosforo total dos pontos amostrais nas quatro campanhas.

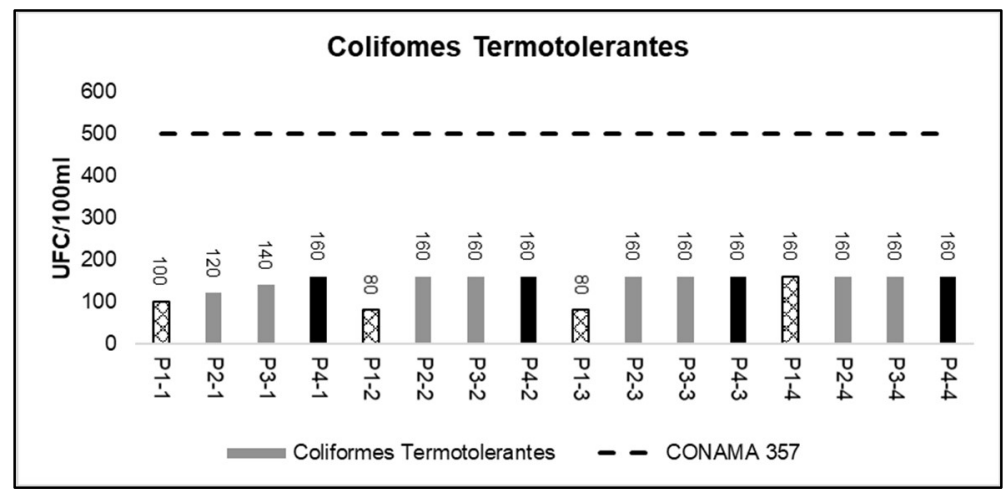

Figura 3: Resultado analítico de coliformes termotolerantes dos pontos amostrais nas quatro campanhas.

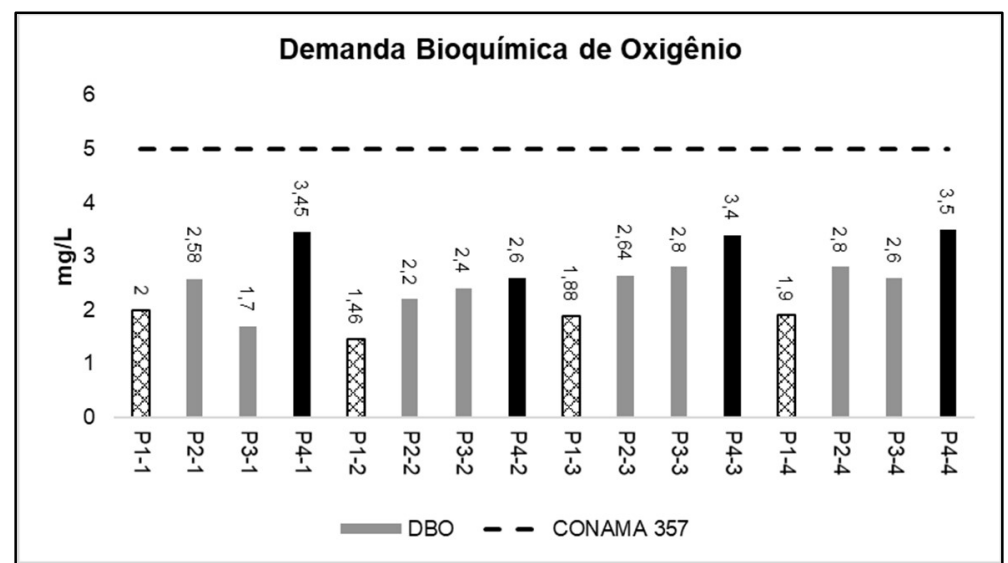

Figura 4: Demanda Bioquímica de Oxigênio nos pontos amostrais nas diferentes campanhas.

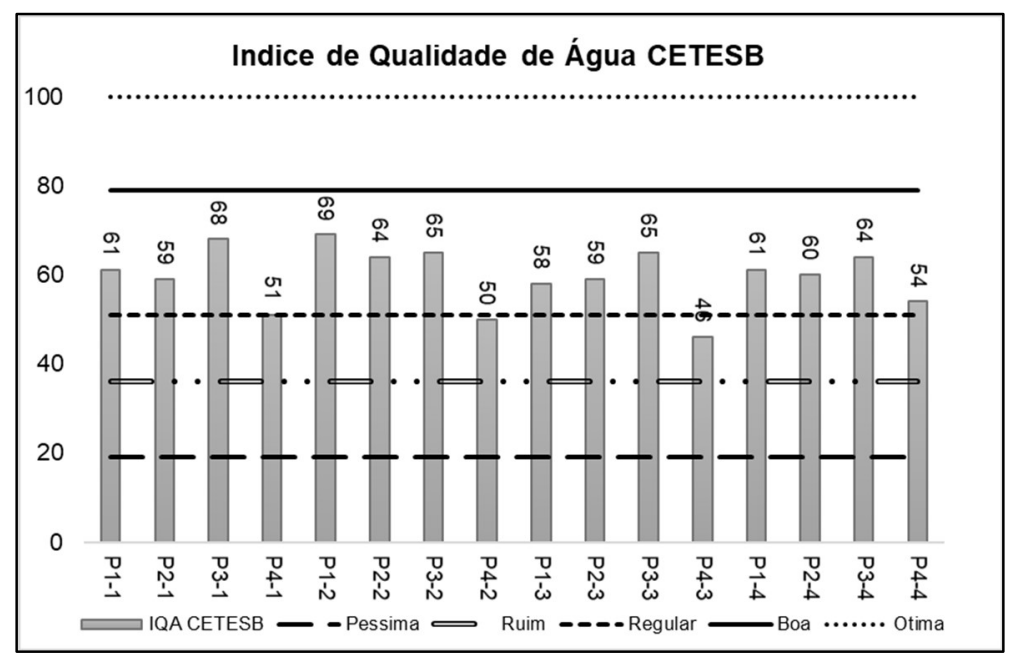

Figura 5: Índice de qualidade de água para os pontos amostrais na diferentes campanhas. 


\section{DISCUSSÃO}

\section{Enquadramento Legal}

As taxas de $\mathrm{pH}$ das amostras variaram de 5,1 até 7,3 conforme podem ver visualizadas na figura 3, os valores mais baixos foram encontrados nos pontos P1 e P4 em diversas campanhas, ou seja, apresentando em maior parte das campanhas caráter ácidos, ficando em desacordo com o recomendado no CONAMA 357 ( $\mathrm{pH}$ de 5 a 9) nos pontos-campanhas P4-2, P1-3, P4-3, P1-4 e P4-4. Estes resultados levemente ácidos em todos os pontos, são semelhantes aos apresentados os de Silva (2018), que encontrou valores ácidos na região Amazônica. Foram observadas elevações nos valores de $\mathrm{pH}$, nos pontos $\mathrm{P} 2$ e P3, provavelmente oriundos do calcário da calagem nos tanques, ou dos sais básicos oriundos da composição da ração dos peixes.

Conforme pode ser observado na figura 4, os pontos P1 e P4 mostraram baixas concentrações de oxigênio dissolvido nas quatro campanhas, permanecendo abaixo do mínimo $(5 \mathrm{mg} / \mathrm{L})$ valor pré-estabelecido na resolução CONAMA 357 para rios de classe II. Esses níveis de oxigênio dissolvidos baixos, estão relacionados à baixa renovação das águas, elevada concentração de matéria orgânica, assim como, o excesso de plantas aquáticas. Nos pontos P2 e P3 foram observadas elevações nas concentrações de oxigênio dissolvido, fato que está relacionado com a aeração nos tanques, já que, o oxigênio dissolvido nas águas é usado intensamente pelos microrganismos decompositores da matéria orgânica, fazendo concorrência às necessidades dos peixes, o oxigênio se dissolve e se incorpora na água por difusão superficial e por ação dos microrganismos fotossintéticos como as algas (SALDANHA, 2019).

$\mathrm{Na}$ figura 6, traz os valores das temperaturas, nestes se pode observa que em todos os pontos e nas diferentes campanhas estão dentro do que recomenda o CONAMA 357/05 para rios de classe II. Entretanto os mesmos sofreram alterações nos pontos P2 e P3 (interior dos tanques), pois as temperaturas aumentaram, provavelmente, pela ausência das matas ciliares, que provocaram um aumento na incidência direta dos raios solares no corpo hídrico. Fato sustentado pelo disposto na CETESB, a temperatura da água é resultado da radiação solar que incide sobre a água, pois exerce grande influência nas atividades biológicas e no crescimento dos organismos e também determina os tipos de organismos que habitam o local, uma vez que os peixes têm uma faixa preferida de temperatura para se desenvolverem, e se este limite for ultrapassado, tanto para mais quanto para menos, os organismos são impactados, apresentando diminuição na taxa de crescimento e espécies mais sensíveis, podem até mesmo ser extintas do local. Águas com temperaturas muito elevadas podem causar dificuldade no processo de digestão dos peixes e redução da sua capacidade de absorver os nutrientes, outra consequência do aumento da temperatura é a diminuição da concentração de oxigênio dissolvido na água que por sua vez dificulta o processo de respiração dos peixes.

A turbidez mostrada na figura 6, encontram-se dentro dos valores pré-estabelecidos no CONAMA357/2005 para águas de classe II em todos os pontos (P1, P2, P3 e P4) nas quatro campanhas, porém podemos observar que no interior dos tanques existe um gradativo aumento, fato que pode ser visto quando confrontamos os pontos P1 com os P2 e P3, isso ocorreu em todas as campanhas, embora segundo Silva 
(2018), a turbidez se mostre bastante heterogênea nos rios da Amazônia. Não se pode descartar a possibilidade desta elevação esteja sendo causada pelo sistema de piscicultura, pois conforme descrito pela CETESB, o aumento na turbidez é causado por materiais em suspensão, como por exemplo, argila, silte, matéria orgânica e inorgânica finamente dividida, compostos orgânicos solúveis coloridos, plâncton e outros organismos microscópicos, fato este também é corroborado por outro estudo, ressalta que $65 \%$ do fosforo e $10 \%$ do nitrogênio presente na ração será convertido em material particulado.

O nitrogênio pode aparecer nas formas de amônia, nitrito, nitrato e nitrogênio orgânico; nos efluentes das atividades de piscicultura advém principalmente da proteína das rações, onde uma parte é excretada pelos organismos na forma de amônia, que será convertido em nitrito e depois nitrato, já o eliminado pelas fezes, está na forma de nitrogênio orgânico. As figuras 8, 9 e 10 mostram as concentrações de nitrogênio nas formas Amônia, Nitrito e Nitrato em todos os pontos e em todas as campanhas se mantiveram dentro dos valores permitidos pelo CONAMA 357/05 para rios de classe II. Entretanto a amônia, é considerada tóxica para os peixes estando acima de $0,2 \mathrm{mg} / \mathrm{L}$, sendo suficiente para se tornar uma toxidez crônica e, por imediato, a reduzir do crescimento e tolerância às doenças (KUBITZA, 1998). No presente estudo, apenas na terceira campanha apresentaram altas concentrações em todos os pontos esteve acima de $0,2 \mathrm{mg} / \mathrm{L}$, podendo estar relacionado à baixa concentração de oxigênio dissolvido, não havendo a nitrificação provavelmente, devido à escassez de bactérias do gênero Nitrossomonas.

Estudos estimam que as taxas de excreção de nutrientes por peixes mantidos por uma dieta com 3540\% de proteína e, com conversão alimentar de 1:1,5 são de aproximadamente $0,025 \mathrm{~kg}$ de nitrogênio e 0,033 $\mathrm{kg}$ de fósforo/kg de biomassa produzida (BOMFIM, 2013). O fósforo total é estabelecido pelo CONAMA $357 / 2005$ é $0,030 \mathrm{mg} / \mathrm{L}$ para ambientes lênticos em rios de classe II. Na figura 10 pode ser observado que em todos os pontos em todas as campanhas houve variações superiores aos recomendados, exceto no ponto P1, que se manteve abaixo deste valor, em todas as campanhas. $\mathrm{O}$ acúmulo desse nutriente na água favorece o desenvolvimento de algas e macrófitas aquáticas, contribuindo para a intensificação da produção primária e com isso, favorecendo o processo de eutrofização e o aumento da concentração de clorofila na água, devido ao crescimento do fitoplâncton no corpo hídrico (BUZELLI et al., 2013). Com o aumento do fósforo no ambiente passa a existir uma maior produção de matéria orgânica do que consumo e decomposição.

A figura 11 apresenta as concentrações de coliformes fecais, não foram obtidas variações entre os períodos chuvoso e secos. No que se refere ao enquadramento legal perante ao CONAMA 357/05. Todas as amostras se mantiveram dentro dos valores permitidos. Isso deve, principalmente, ao corpo hídrico sofrer pouca influência de esgotos domésticos por esta localizado em zona rural.

A DBO é um dos parâmetros mais importantes, está relacionado com a quantidade de oxigênio dissolvido necessário na água que permite aos microrganismos decomporem estes materiais. Na figura 12, os valores de DBO analisados nos quatros pontos (P1, P2, P3 e P4) em todas as campanhas estão abaixo dos limites que a resolução 357/2005 estabelece para aguas de classe II. 


\section{Do enquadramento legal com o CONAMA 430/2011 para o ponto P4 e comparação P1}

O ponto P4 pode ser considerado como ponto de lançamento de efluentes, pois é resultante da descarga dos tanques de piscicultura, desta forma também será enquadrado na resolução 430/2011. Outro fator relevante é a comparação com valor de P1 que é antes de entra nos sistemas de piscicultura. Os valores de pH que segundo está resolução 430/2011 devem estar entre 5 a 9, os mesmo se mantiveram em conformidade com que prega a resolução em todas as quatro campanhas, quando comparamos com os valores antes de passar nos tanques não são observadas modificações significativas.

O oxigênio dissolvido não há recomendações quanto a limitação na resolução 430/2011, mas no que se refere a comparação entre os Pontos P1 e P4 observamos uma tendência de declínio nas concentrações, mesmo depois dos processos de aeração, ocorridas no interior dos tanques (pontos P2 e P3). Esse fato se deve, provavelmente, ao crescimento de microrganismos, que consomem o oxigênio disponível para decomposição da matéria orgânica que foi disponibilizada para crescimento dos peixes (MARTINS, 2016).

A temperatura abaixo dos $40^{\circ} \mathrm{C}$ no ponto $\mathrm{P} 4$ em todas as quatro campanhas, confirmando a conformidade com a regulamentação do CONAMA 430/2011, fato já esperado pois no processo de uso da água para atividade de piscicultura não há elevações brutas da temperatura, também não são notadas modificações significativas quando confrontados os resultados de P1 com os de P4, isso para todas as campanhas (SILVA et al., 2012).

A turbidez não é um parâmetro legislado na resolução 430/2011, entretanto é observado aumento gradativo nos seus valores em todas as campanhas quando confrontamos os pontos P1 e P4, isso se deve a elevação das quantidades de material particulado oriundo da alimentação dos peixes no sistema de piscicultura (KUBITIZA, 2007).

No que se refere as concentrações de nitrogênio nas formas de nitrito e nitrato este não são previstos valores de referência para lançamentos na resolução 430/2011, porém é observado nas campanhas 1, 2, 4 um aumento nas concentrações de nitrito, quando comparamos os resultados dos pontos P1 e P4, no que tange aos resultados de nitrato não foram identificadas relações significativas. As concentrações de fosforo total estiveram em altas concentrações quando comparado os valores de P1 e P4 em todas as campanhas este fato foi observado, no que se refere ao enquadramento legal do fosforo segundo a resolução 430/2011 não contempla este parâmetro.

A demanda bioquímica de oxigênio não houve decaimento nos valores das concentrações, e sim um aumento quando comparamos os valores das concentrações do ponto P1 e do ponto P4, fato ocorreu em todas as campanhas, desta forma está em desconformidade com que prega o CONAMA 439/2011 que recomenda uma redução de $60 \%$ da taxa de DBO. Este está ligado principalmente ao aumento na disposição de matéria orgânica advindo da ração e dos dejetos dos peixes. Corroborado pelos resultados encontrados pelos Baccarin (2002), que avaliou o impacto ambiental da produção de tilápia do Nilo sob diferentes manejos alimentares, verificou que com o incremento da biomassa dos peixes ocorreu uma redução gradativa dos teores de oxigênio dissolvido e o aumento dos valores de turbidez e de material em suspensão do efluente, 
independente da dieta fornecida. Este fato foi associado ao aumento do arrecadamento, ao aumento dos dejetos e à decomposição da matéria orgânica.

\section{Do índice da qualidade de água}

A figura 14 traz os índices de qualidade de água em todos pontos e campanhas, neles é possível observar que os valores de IQA quando comparamos os valores a montante (P1) e jusante (P4) se nota que houve queda nos valores de IQA, fato observado em todas as campanhas, alterando sua classificação segundo a CETESB de água de bom para regular. Isso se deve devido a acidez, carga de matéria orgânicas de origem vegetal e elevada turbidez das águas, que embora sejam características típicas dos rios amazônicos de águas brancas (SIOLI, 1957), houve incrementos destes parâmetros após passa pelo sistema de piscicultura. Não foram identificadas variações significativas entre os períodos da pouca incidência das chuvas e o de chuvas abundantes.

No que se refere aos pontos dentro do tanque (P2 e P3) os índices de qualidade de água se mantiveram na zona boa, conforme classificação proposta pela CETESB, e com valores superiores aos apresentados a montante (P1), isso se deve principalmente os valores de oxigênio dissolvido são maiores nos pontos P1 e P2, gerados pelos sistemas de aeração dos tanques, e este parâmetro no cálculo do IQA apresenta maior peso no cálculo quando comparado com os demais.

\section{CONCLUSÕES}

A qualidade dos efluente gerados nos tanques incidem alterações que possivelmente comprometem o ambiente aquático em relação à quantidade de concentração de fósforo que permaneceram com seus níveis superior aos permitidos da resolução CONAMA 357/05, o fósforo é um dos mais importantes fatores limitantes à vida dos organismos aquáticos e seu acúmulo em uma massa da água, é de importância fundamental no controle ecológico das algas, mais também o fósforo é o principal componente para se avaliar a capacidade suporte do corpo da água da eutrofização, de produtividade e danos ambientais. Embora a maioria dos parâmetros se tenham mantido dentro dos padrões preestabelecidos nas resoluções CONAMA 430/05 e CONAMA 357/05, no confronto entre pontos de montante (P1) e jusante (P4), os resultados revelaram que ocorre diferenças significativas, revelando desta forma que o corpo hídrico pode sofre alterações na sua qualidade, dependendo da sua capacidade de alto depuração.

Desta forma mesmo não ocorrendo diferenças significativas nos pontos montante e jusante, deve-se ter o cuidado no manejo, pois elas estão relacionadas com o meio aquático e na alteração de uma pode ocasionar na morte até mesmo total dos peixes nos viveiros devido a sua sensibilidade, quanto nas variações precipitadas principalmente do oxigênio dissolvido na água.

As cargas de DBO, amônia e fósforo devem ser avaliadas como fontes que contribuem na poluição nos corpos d'água, ou seja, os principais impactos observados na Estação de Santa Rosa a eutrofização e o comprometimento da qualidade da água do efluente no corpo receptor. O IQA se mostrou um eficiente na avaliação dos pontos P1 e P4 mostrando uma queda na classificação da qualidade de boa para regula, porém 
não é uma ferramenta avaliativa eficiente para mensurar impactos no interior dos tanques escavados.

\section{REFERÊNCIAS}

ABNT. Associação Brasileira de Normas Técnicas. NBR 9898: Preservação e técnicas de amostragem de efluentes líquidos e corpos receptores. Rio de Janeiro: ABNT, 1987.

ANDRADE, M. L.. Criação de Tilápias. São Paulo: Nobel, 1989.

APHA. American Public Health Association. Standard methods for the exammination of water and wastewater. 22 ed. Washington: APHA, 2012.

BACCARIN, A. E.. Impacto ambiental e parâmetros zootécnicos da produção de tilápia do Nilo (Oreochromis niloticus) sob diferentes manejos alimentares. Tese (Doutorado) - Universidade Estadual Paulista, Jaboticabal, 2002.

BASTOS, R. K. X.. Utilização de Esgotos Tratados em Fertirrigação, Hidropônia e Piscicultura. Rio de Janeiro: ABES, 2003.

BOMFIM, M. A. D.. Estratégias Nutricionais para Redução das Excreções de Nitrogênio e Fósforo nos Sistemas de Produção de Peixes no Nordeste: Sustentabilidade Ambiental e Aumento da Produtividade. Rev. Cient. Prod. Anim., v.15, n.2, p.122-140, 2013.

BRABO, M. F.. Piscicultura no Estado do Pará: situação atual e perspectivas. Acta of Fisheries and Aquatic Resources, Sergipe, v.2, n.1, p.1-7, 2014. DOI: https://doi.org/10.2312/Actafish.2014.2.1.i-vii

BRASIL. Resolução CONAMA n. 357 de 17 de março de 2005. Dispõe sobre a classificação dos corpos de água e diretrizes ambientais para o seu enquadramento, bem como estabelece as condições e padrões de lançamento de efluentes, e dá outras providências. Brasília: DOU, 2005.

BRASIL. Resolução CONAMA n. 430 de 13 de maio de 2011. Dispõe sobre as condições e padrões de lançamento de efluentes, complementa e altera a Resolução n. 357, de 17 de março de 2005. Brasília: DOU, 2011.

BUZELLI, G. M.; CUNHA-SANTINO, M. B.. Análise e diagnóstico da qualidade da água e estado trófico do reservatório de Barra Bonita, SP. Revista Ambiente \& Água, Taubaté, v.8, n.1, p.186-205. 2013. DOI: http://dx.doi.org/10.4136/ambi-agua.930

KUBITZA, F.. Qualidade da água na produção de peixes. Parte II. Revista Panorama da Aquicultura, v.8, n.46, p.36-41, 1998.

LEIRA, M. H.; CUNHA, L. T.; BRAZ, M. S.; MELO, C. C. V.; BOTELHO, H. A.; REGHIM, L. S.. Qualidade da água e seu uso em pisciculturas. Revista PUBVET. Maringá, v.11, n.1, p.1117, 2017.
LIBÂNIO, M.. Fundamentos de qualidade e tratamento de água. Campinas: Átomo, 2005.

MARTINS, L. A. P.. Avaliação da qualidade da água de viveiros de piscicultura de pequeno porte associados à suinocultura. Ouro Preto: UFOP, 2016.

MASSOUD, M. F.. Assessment of water quality along a recreational section of the Damour River in Lebanon using the water quality index. Environmental Monitoring and Assessment, v.184, n.7, p.4151-4160, 2012.

MORAIS, J. P.; RIBEIRO, D. K.; COUTINHO, F. C.; OLIVEIRA, K. M.. Qualidade da água na piscicultura: um estudo de caso em comunidades rurais do município de formiga - Mg. In: SIMPÓSIO BRASILEIRO DE RECURSOS HÍDRICOS, 21. Anais. 2015.

QUEIROZ, J. F.; BOEIRA, R. C.; SILVEIRA, M. P.. Coleta e preparação de amostras de sedimentos de viveiros de aquicultura. Jaguariúna: Embrapa Meio Ambiente, 2004.

RIRSCH, F. A.. A Piscicultura no Brasil. São Pedro: GESPIANOS, 2013.

SALDANHA, E. C.; NASCIMENTO, T. S. R.; RODRIGUES, R. Avaliação dos danos sobre a qualidade de Água por efluentes de piscicultura: estudo de caso Santa Rosa, Santarém/Pará. Brasília: ENFOC, 2019.

SILVA, A. M. C. B.. Perfil da piscicultura na região sudeste do estado do Pará. Dissertação (Mestrado em Ciências Animal) - Universidade Federal do Pará, Belém, 2010.

SILVA, L. J. S.; PINHEIRO, J. O. C.; CRESCÊNCIO, R.; CARNEIRO, E. F.; PEREIRA, B. P.; BRITO, V. F. S.. Tecnologia e Desenvolvimento rural: Aspectos do Cultivo de Tambaqui no Município de Rio Preto da Eva, AM. Revista Terceira Margem Amazônia, Manaus, v.3, n.10, p.170-196, 2018.

SILVA, S. F.; FERRARI, J. L.. Análise espacial de atributos físico-químicos da água em viveiros de piscicultura com geometrias diferentes. Centro Científico Conhecer, Goiânia, v.8, n.14, p.51-63, 2012.

SINGH, K. P.; MALIK, A.; SINHA, S.. Water quality assessment and apportionment of pollution sources of Gomti River (India) using multivariate statistical techniques - a case study. Analytica Chimica Acta, v.538, n.1-2, p.355-374, 2005.

SOARES, C.. Análise das implicações sociais, econômicas e ambientais relacionadas ao uso da piscicultura: O Caso Fazenda Princesa do Sertão, Palhoça/SC. Dissertação (Mestrado em Engenharia de Produção) - Universidade Federal de Santa Catarina, Florianópolis, 2003.

SOUZA, S. M. D.. Qualidade de água para cultivo de peixes. Porto Alegre: UFRGS, 2010.

A CBPC - Companhia Brasileira de Produção Científica (CNPJ: 11.221.422/0001-03) detém os direitos materiais desta publicação. Os direitos referem-se à publicação do trabalho em qualquer parte do mundo, incluindo os direitos às renovações, expansões e disseminações da contribuição, bem como outros direitos subsidiários. Todos os trabalhos publicados eletronicamente poderão posteriormente ser publicados em coletâneas impressas sob coordenação da Sustenere Publishing, da Companhia Brasileira de Produção Científica e seus parceiros autorizados. Os (as) autores (as) posteriormente ser publicados em coletâneas impressas sob coordenação da Sustenere Publishing, da Companhia Brasileira de Produção Científica e seus pã
preservam os direitos autorais, mas não têm permissão para a publicação da contribuição em outro meio, impresso ou digital, em português ou em tradução. 